\title{
The Further Study of the Blended Learning Model of the Video-aural-oral Course-the Combination of Web-based Learning, Flipped Classroom and Face-to-Face Instruction
}

\author{
Xiaomei Liu ${ }^{1, ~ *, ~ L i n d o n g ~ Z h a n g ~}{ }^{2}$, Shufang Zhang ${ }^{3}$, Yingtao Tian ${ }^{4}$ \\ School of Humanities and Law, Beijing University of Chemical Technology, Beijing, China \\ Email address: \\ Liuxm10@163.com (Xiaomei Liu) \\ ${ }^{*}$ Corresponding author \\ To cite this article: \\ Xiaomei Liu, Lindong Zhang, Shufang Zhang, Yingtao Tian. The Further Study of the Blended Learning Model of the Video-aural-oral \\ Course-the Combination of Web-based Learning, Flipped Classroom and Face-to-Face Instruction. Education Journal. \\ Vol. 9, No. 3, 2020, pp. 64-72. doi: 10.11648/j.edu.20200903.12
}

Received: April 22, 2020; Accepted: May 18, 2020; Published: May 27, 2020

\begin{abstract}
The teaching model of blended learning with flipped classroom has been prevalent in China in recent years, but the empirical study in this regard is relatively less. On the basis of related theories, the innovative type of blended learning, which was a combination of mobile terminal learning, web-based autonomous learning, flipped classroom and face-to-face instruction, was designed. The purpose of this study was to enhance students' autonomy in their e-learning, to raise the efficiency of the face-to-face instruction of the video-aural-oral course and to improve students' listening and speaking ability. The new teaching model was tested on 156 non-English majors in Grade 2017 in Beijing University of Chemical Technology for two terms. The correlation coefficient of the scores of the web-based autonomous learning and the scores of the objective listening in the final exams was made. The criterion of the dynamic assessment of the oral test was designed. The different forms of the oral tests, which were assessed on the mobile terminal, by the peer and by the teacher, were adopted. The learning outcomes were collected and analyzed to verify the effect of this teaching model. The results show that most of the subjects did the web-based autonomous learning earnestly. The subjects' listening and oral ability improved. In this study, the teacher's leading role was manifested in all aspects of teaching: carefully designing the teaching content of the flipped class, raising the efficiency of the face-to-face instruction of the video-aural-oral class, closely tracking the subjects' learning processes online and providing them with timely, personalized online and offline guidance. The students' principal part was manifested in the interaction with the resources, motivated autonomous learning, learning before class, peer study, teamwork and self-reflection. All of these are the key elements in this teaching model. The conclusion has important reference significance on the research of blended learning.
\end{abstract}

Keywords: Mobile Terminal Learning, Web-based Autonomous Learning, Flipped Classroom, Face-to-Face Instruction, Blended Learning

\section{Introduction}

\subsection{The Present State of the Video-Aural-Oral Course in the University}

The web-based autonomous learning of listening in English for non-English majors in Beijing University of Chemical Technology (BUCT), which was the supplemantory part of the Video-Aural-Oral Course, started in 2006. In September 2012, the class hours of College English Course, which consists of the Integrated Course and the Video-Aural-Oral Course, were reduced from 256 to 192 . There are only 16 class hours left for the face-to-face instruction of the Video-Aural-Oral Course. In 2017, the mobile terminal learning was adopted in BUCT. Both the mobile terminal learning and the web-based autonomous learning have become the means of making up the reduced class hours to increase students' input of listening and to improve their aural-oral ability. However, there exist some deficiencies in the learning and instruction model. (1) The learning efficiency. From the questionnaire conducted on 146 students in Grade 2014, a third of whom downloaded the answers on the Internet in the web-based autonomous learning. 
On the other hand, as it's the first time that the mobile terminal learning was practised in BUCT, how to ensure the effect of that is something the teachers had to deal with. (2) The diverse needs of learning. In the face-to-face instruction of the Video-Aural-Oral Course, the textbook, New Standard College English Real Communication Listening and Speaking (New Standard College English) [1] is used. From the questionnaire conducted on 137 students in Grade 2015, more than a third of whom didn't receive any training of listening comprehension before they entered the university. With the only one textbook, the diverse needs of students can hardly be fulfilled. (3) The form and the assessment of the oral test. In the former oral test, the teacher used to mark students' oral ability with their recordings made on the computer in the language laboratory; the assessment of the face-to-face oral test between the teacher and the student is unitary. None of them can tap the learning potential of students.

\subsection{Blended Learning and Flipped Classroom}

Blended learning, first defined by the Sloan Consortium, means the integration of face-to-face instruction with online learning $[2,3]$. Three features of blended learning were posed by Yen and Lee: first, the emphasis has been shifted from the teacher to the student; second, blended learning enhances the interaction between students and students, the interaction between teachers and students, the interaction between students and contents as well as the interaction between students and external resources; third, the assessment mechanism of combining formative assessment with summative assessment has been applied [4]. The concept of blended learning was first put forward in China by Ke-kang $\mathrm{He}$, who holds the opinion that blended learning combines the strength of face-to-face instruction with online learning, which could both give full play to the teacher's leading role of guiding, enlightening and monitoring the students in the teaching processes and also to the students' initiative and creativity [5]. Since 2013, the concept of blended learning has evolved. The application of mobile technology has been incorporated to it. The concept of "the integration of face-to-face instruction with online learning" has formally changed to "the learning environment based on the mobile communication equipment, the online learning environment and the face-to-face instruction environment" [6].

Flipped Classroom/Inverted Classroom is a kind of teaching model that flips the traditional learning process with the help of modern technology. Jonathan Bergmann and Aaron Sams [7] first adopted this model.

Under the background of " Internet + " and with the development of information technology, teachers have been armed with modern means of teaching methods, which present the opportunities of promoting the evolvement of blended learning. How to strike a balance between face-to-face instruction and online learning is the key to teaching [8]. Therefore, the educational circles in China have carried out the research on blended learning [9] and flipped classroom [10], but the empirical study in this regard is relatively less [9]. On account of the poor efficiency of web-based autonomous learning, BUCT conducted the research on blended learning in 2015 [11]. A series of measures were taken to prevent students in Grade 2015 from downloading the answers on the Internet, which enhanced the efficiency of their autonomous learning and the results turned out to be fruitful. On the basis of that, "The New Engineering Instruction Reform Project" was funded in BUCT to carry out the further research on face-to-face instruction and online learning to improve the teaching quality of College English for the non-English majors.

\subsection{The Objectives of the Research}

With the above theory, this research integrated "mobile terminal learning", "web-based autonomous learning", "flipped classroom", "face-to-face instruction" into one model with the following objectives: (1) The principal part of students. To bring the students' initiative to learn into full play to enhance their input and output quality. (2) The leading role of teachers. To give free rein to teachers' leading role of monitoring and controlling students' learning processes in an all-around way and provide them with personalized guidance. (3) Individualized instruction. To combine the model of "flipped classroom" with face-to-face instruction to teach students according to their aptitude. (4) Novel assessment. To adopt the form of "machine assessment + peer assessment + teacher assessment" in the oral test to evaluate the students' oral ability more objectively.

\section{The Subjects and Measurement Tools}

The subjects were non-English majors in Grade 2017 in BUCT, from the intermediate classes (neither the advanced, nor the adjustment classes). They were from the following classes and majors: Functional Material 1701-02; Mathematics 1707-Applied Chemistry 1707; Machinery 1707-08-14. There were 156 of them.

The measurement tools included: (1) the scores of the placement test; (2) the listening scores of online exams of $\mathrm{New}$ Horizon College English: Speaking Listening Viewing (Book 1 and Book 2) [12], the scores of objective listening and dictation in the final exams of Grade $C$ (the first term) and Grade B (the second term); (3) the scores of the oral tests of Grade C and Grade B.

\section{The Viwes on the Research}

\subsection{The Interaction Hypothesis}

"The Interaction Hypothesis" is also referred to as "The Input, Interaction and Output Model". The integration model of this hypothesis was put forward by Gass in 2005 and there are four stages in the second language acquisition. The first stage is that the perceived input of learners is affected by four factors: the frequency of input, the prior knowledge, the emotional factors and attention; the perceptible input enables the further analysis of the next stage. The second stage is that learners adjust their language in their communication with the 
native speakers through negotiation of meaning. With the function of the prior knowledge and UG (Universal Grammar), the perceived input is converted into the understood input. The third stage is the absorption stage. Absorption means a kind of psychological process in which the learners adjust their language input with their grammar. At this stage, the learners undergo the psychological processing of language knowledge, making a comparison between the input information and their prior internalized knowledge. The learners generalize the knowledge and form the memory chain, which is also one of the sources of fossilization. The fourth stage is integration, in which the absorbed knowledge is integrated by the learners themselves. The integration includes two forms: the internalized grammar which was developed from the new language knowledge; the knowledge stored for further processing [13].

\subsection{The Output-driven Hypothesis}

The "Output-driven Hypothesis", first raised by Qiufang Wen in 2013, includes two parts. First, as far as the learning process is concerned, the internal drive of output is greater than that of input. The drive of output not only promotes the application of receptive language knowledge, but also arouses the learners' desire for new knowledge. Second, as far as teaching objectives are concerned, to foster the abilities of speaking, writing and translation may satisfy the needs of society better. Therefore, speaking, writing and translation, which are the expressive skills, are explicit assessment objectives while listening and reading, which are the receptive skills, are only implicit goals. In line with the actual employment needs of society, the learners can choose one or several output skills among speaking, writing and translation as their learning goals [14].

\section{The Innovative Blended Learning Model of the Video-Aural-Oral Course}

The innovative type of the blended learning model of the Video-Aural-Oral Course was designed with the four elements of curriculum framework by Tyler [15] as is shown in Figure 1.

The teaching objective $\rightarrow$ The teaching content $\rightarrow$ The presentation of the teaching content $\rightarrow$

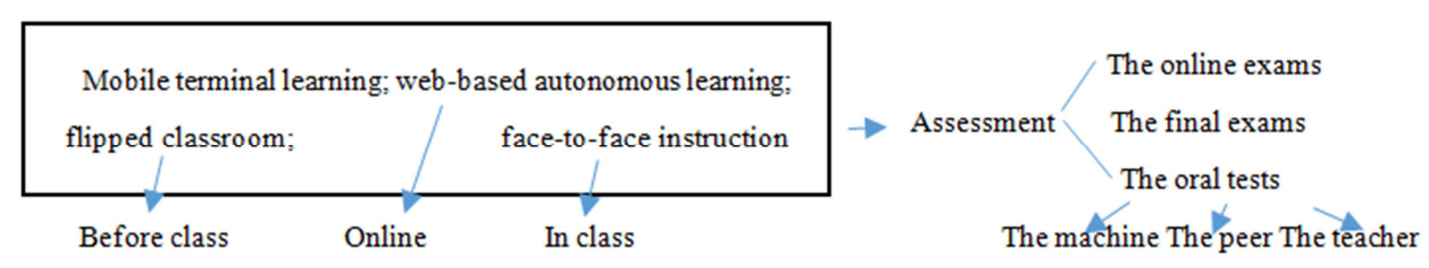

Figure 1. The flow chart of the innovative type of the blended learning model of the Video-Aural-Oral Course.

\subsection{The Teaching Objective}

The objective of College English is to develop students' application ability of English, to enhance the awareness and the ability of intercultural communication and at the same time to develop the ability of independent learning and to improve their comprehensive cultural attainment so that they will be able to communicate effectively in their studies, life, social interactions as well as future careers to meet the needs of China, society, the university and personal development [16].

\subsection{The Teaching Content}

The objective of this teaching model was to be achieved with the combination of "mobile terminal learning + web-based autonomous learning + flipped classroom + face-to-face instruction". The teaching content includes these items. First, the content of "mobile terminal learning + web-based autonomous learning". The content of the former was selected from the item bank of FIF foreign language learning resource base (http://lib.fifedu.com), whose topics were related to campus life, communication and oral English training of College English (Band 4). The content of the latter was New Horizon College English: Speaking Listening Viewing (New Horizon College English) [12]. Second, the content of "flipped classroom + face-to-face instruction" encompassed New Standard College English and 5 sets of loose leaf listening exercises whose form and degree of difficulty were similar to those of College English (Band 4). In order to satisfy the subjects' diverse needs for learning, some video and audio materials related to the topics of the textbooks were incorporated into their independent learning.

\subsection{The Presentation of the Teaching Content}

\subsubsection{Mobile Terminal Learning + Web-based Autonomous Learning}

Figure 2 is the flow chart of mobile terminal learning + web-based autonomous learning.

Teachers $\rightarrow$ post the leaming tasks $\rightarrow$ track the progress $\rightarrow$ answer questions online $\rightarrow$ collect the reports $\rightarrow$ analyze questions in class.
Students $\rightarrow$ leam on schedule $\rightarrow$ fill in self-assessment reports $\rightarrow$ answer questions in class $\rightarrow$ take the mobile terminal tests $\rightarrow$ take the online exams.

Figure 2. The flow chart of mobile terminal learning + web-based autonomous learning. 
At the outset of each term, the teacher posted the learning tasks for autonomous learning. (1) The mobile terminal learning. The subjects were asked to finish one lesson within two weeks and a half. There were four learning tasks. They would get 1 score upon the completion and 0.25 score would be deducted if the task was not completed as scheduled or not fully finished. (2) The web-based autonomous learning. The subjects were asked to finish one lesson within one week and a half. There were ten learning tasks. They would get 4 scores upon the completion of New Horizon College English and 0.4 score would be deducted if the task was not completed as scheduled or not fully finished. The teacher tracked the learning processes as scheduled, collecting the self-assessment reports, observing the learning development and answering questions online. The teacher explained the questions which shared some common features such as problems on grammar, sentence structure in class.

The subjects finished their learning tasks as scheduled, filling in the self-assessment reports which included the self-assessment of their listening and speaking ability, the frequency of doing the exercises of the mobile terminal learning and the web-based autonomous learning, the difficulties they were faced with, etc. They could also communicate with the teacher on the phone or send messages to the teacher. The self-assessment reports of FIF foreign language learning were completed on the subjects' mobile terminals while those of New Horizon College English were finished in the language laboratory.

\subsubsection{Flipped Classroom + Face-to-Face Instruction}

Figure 3 is the flow chart of flipped classroom + face-to-face instruction.
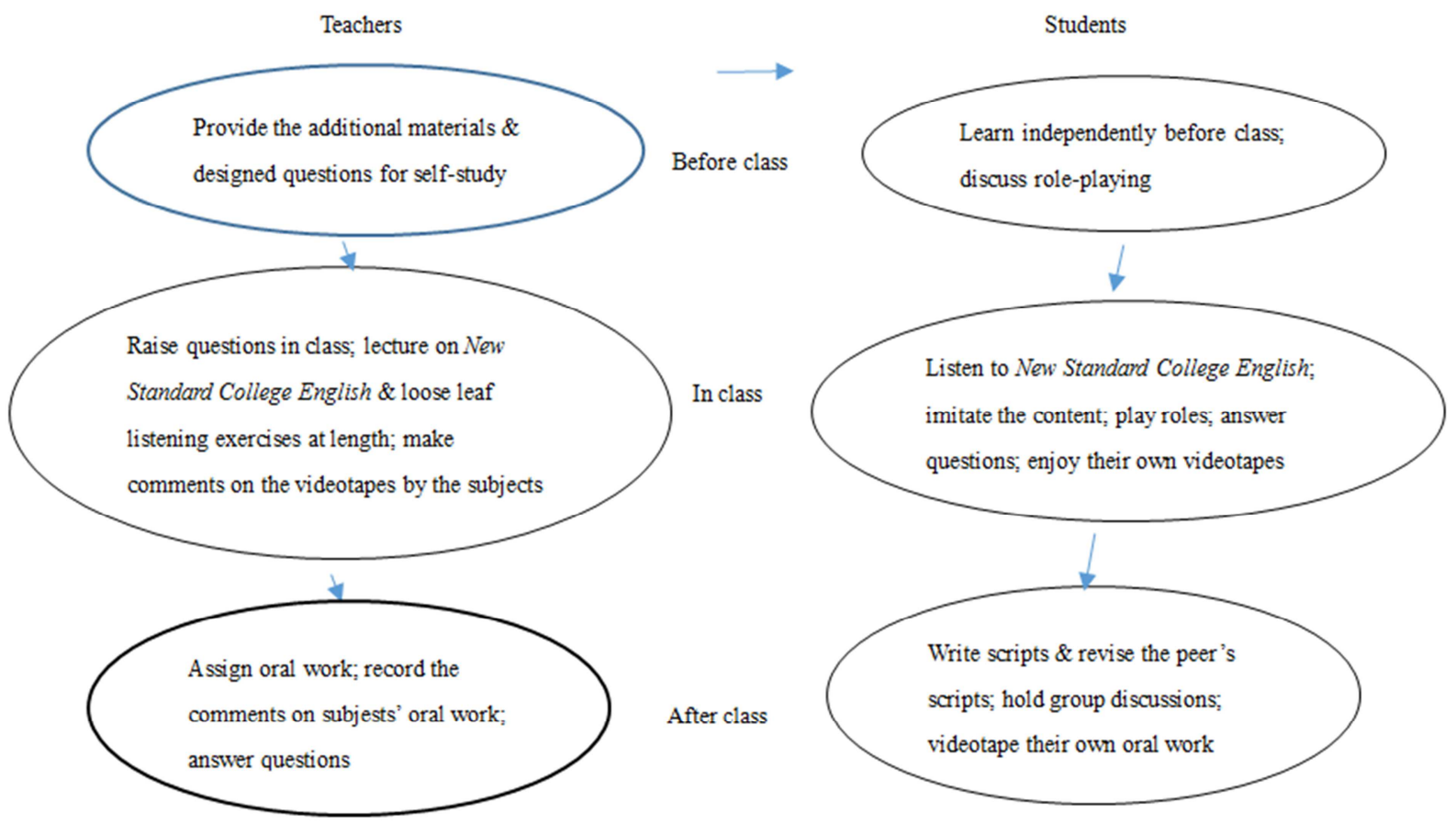

Figure 3. The flow chart of flipped classroom + face-to-face learning

First, the learning environment, supplementary materials and the use of the textbook. As the subjects' educational backgrounds were diverse, a truly "student-centered" environment was designed with the notion that a teacher who creates a truly "student-centered" classroom understands and respects the diversity of learning strengths within any group and offers choices in how information and skills will be acquired [17]. A genuinely "student-centered" classroom is a democratic educational environment that enables students to equitably develop their individual learning styles to meet the diverse demands of school and life with increased confidence and competence [17]. Moreover, according to the theory of limited attention resources, the processing power, which is the processing mechanism of cognitive attention of the human brain, is limited. Cognitive overload may lead to poor take-in of the input received [18]. Therefore, for each lesson, the teacher added two or three videos downloaded from CCTV dialogues, VOA news and BBC news to the flipped classroom + face-to-face instruction. The degrees of difficulty of the supplementary materials were different so as to satisfy the subjects' diverse needs. Furthermore, the teaching task of New Standard College English was adjusted and the part of its Listening in was left to the subjects for independent study and role-playing.

Second, the ways of carrying out the activities and tasks of teaching and learning. According to the "The Interaction Hypothesis", language learning is triggered under the pressure of communication. The interaction study is to test the relation between communication and language acquisition and also to test the cognitive mechanism of attention and awareness that coordinates the two of them. The results of Gass' study verified the fact that input and interaction enhance language 
acquisition. In the process of interaction, negotiation for meaning, especially the interaction adjustment which was triggered by negotiation for meaning of the native speakers, can promote language acquisition, because negotiation for meaning can combine input, the capacity for learning, especially selective attention, and output together [13]. Therefore, the subjects were arranged in groups in which there were six or seven of them who discussed the oral work, corrected the peer's scripts which were videotaped subsequently. The mobile terminal learning, the web-based autonomous learning and the independent learning in the flipped classroom all belonged to the frequency of input; the group interaction may help the subjects to associate language input with meaning and to form the chains of memory, which became the internalized knowledge and was manifested in the form of output. The following were the specific procedures.

i. Before Class

The teacher provided the subjects with supplemantary materials such as the videos, the designed questions and assigned the tasks for independent learning. For example, one of the videos was Obama's speech My Education, My Future (selected from NetEase September 1, 2015). The designed questions were:

a. What responsibilities did Obama focus on in his speech? How to fulfil the responsibilities?

b. What difficulties do you have in learning English? How to solve them?

c. What goals can you set for your college education? Write them down and read them to the class. (These goals can be small or big, short-term or long-term.)

Another example was Cyber Security Report (selected from CCTV, China 24, January 4, 2016)

The designed questions were:

a. How many pieces of information could have been leaked from the websites across China? What serious consequences have they caused?

b. How to protect privacy from being leaked?

The contents of these videos were real and were likely to kindle the subjects to start their discussion and oral practice. The subjects were asked to watch the videos after class and answer the designed questions. They took notes of the difficulties in the process of learning which would be discussed in class.

ii. In Class

The teacher spent 20 minutes to discuss questions on the videos with the subjects, then spent 10 minutes to raise questions on New Horizon College English, for instance:

a. Do you surf the Net? (from Unit 9 Book 1, New Horizon College English)

b. What's on at the cinema? (from Unit 2 Book 2, New Horizon College English)

The rest of the 60 minutes were devoted to teaching activities which were conducted in the following manner: with regard to the Outside View in New Standard College English, the stress was laid on the expansion of the subjects' horizon and their getting acquainted with the Western culture; with regard to the loose leaf listening exercises, the stress was placed on the training of listening skills such as prediction, making inference or guess according to the context, understanding the information according to the sense group. The Outside View and the loose leaf listening exercises needed to be dealt with intensive listening and detailed explanation. Finally, the teacher exhibited the excellent videos by the subjects, made comments on the completion of the mobile terminal learning as well as the autonomous learning of New Horizon College English and played the teacher's recorded comments on the videos by the subjects.

iii. After Class

The teacher assigned the oral work, for instance, "My University Days"; "The Most Unforgettable Event in My Life".

"Language output will promote second language acquisition by means of the learner's self-awareness and conscious process [19]". Therefore, the subjects were asked to write scripts, which were corrected, polished by the peers and made videos later.

As Goodyear emphasized, the so-called blending, was not only the combination of face-to-face instruction with online education, but the blending of teaching and tutoring students in the "student-centered" environment [19]. After class, the teacher watched the video by the subjects, made recorded comments on each of their performances including pronunciation, semantic meaning and grammar mistakes. Meanwhile, the teacher gave the subjects individualized guidance and feedback which were based on their recorded performances on the computer or the mobile terminal.

\subsection{Assessment}

The scores of the assessment included the following items: (1) The scores of the online exam of New Horizon College English accounted for 5\%. The online exam of New Horizon College English, whose content was taken from the original textbook, was held once a term and lasted 40 minutes. The full marks were 50. (2) The completion scores for FIF foreign language learning + New Horizon College English accounted for $5 \%(1 \%+4 \%)$. (3) The scores of the oral test accounted for $5 \%$ and the mean of "machine assessment + peer assessment + teacher assessment" was adopted. (4) The listening assessment was part of the final exam and accounted for $30 \%$ of the exam paper in which the objective listening scores accounted for $20 \%$ and those of dictation accounted for $10 \%$ (All of the above scores took up 31.5\% of the full assessment of College English).

The oral tests were designed in two ways: the dynamic assessment [20] and the machine assessment. In the dynamic assessment, there are the evaluators' involvement and interaction. As Qiufang Wen pointed out: "When it comes to the assessment, the priority is that the teacher should inform the students of the criteria of the content of the assessment, even permit them to participate in the prescription of the criteria. The process of participation is the process of learning and understanding the criteria. On top of teacher assessment, peer assessment should be included [20]." The strategy of peer assessment contributed to arousing the students' interest in 
learning and raising the efficiency of their learning [21]. The criterion of the dynamic assessment of the oral test is seen in Table 1 .

Table 1. The criterion of the dynamic assessment of the oral test.

\begin{tabular}{|c|c|}
\hline Scores & The Criterion \\
\hline 1 & $\begin{array}{l}\text { Pronounce words vaguely, speak with single word or sentence; } \\
\text { seriously hindered from communication. }\end{array}$ \\
\hline 2 & $\begin{array}{l}\text { Pronounce words with a strong accent of the mother tongue; } \\
\text { hindered from being understood because of too many grammar } \\
\text { and vocabulary mistakes; pause frequently from communication } \\
\text { because of poor vocabulary. }\end{array}$ \\
\hline 2.5 & $\begin{array}{l}\text { Pronounce words with the accent of the mother tongue; hindered } \\
\text { from being understood because of too many grammar and } \\
\text { vocabulary mistakes; pause now and then from communication. }\end{array}$ \\
\hline 3 & $\begin{array}{l}\text { Poor articulation due to inaccurate pronunciation; there are some } \\
\text { grammar and vocabulary mistakes in the speech; pause } \\
\text { occasionally but still can be understood. }\end{array}$ \\
\hline 3.5 & $\begin{array}{l}\text { Poor articulation due to inaccurate pronunciation; there are few } \\
\text { grammar or vocabulary mistakes in the speech; speak with simple } \\
\text { sentence structure; the sentences are not coherent. }\end{array}$ \\
\hline 4 & $\begin{array}{l}\text { Poor articulation due to the mispronunciation of a few words; } \\
\text { there are few grammar or vocabulary mistakes in the speech; } \\
\text { simple sentence structure; the sentences are coherent on the } \\
\text { whole. }\end{array}$ \\
\hline 4.5 & $\begin{array}{l}\text { Slightly defective pronunciation; very few grammar or } \\
\text { vocabulary mistakes; rich vocabulary; clear argument and } \\
\text { evidence; rather fluent speech. }\end{array}$ \\
\hline 5 & $\begin{array}{l}\text { Good pronunciation; almost no grammar or vocabulary mistakes; } \\
\text { rich vocabulary; complex sentence structure; fluent speech. }\end{array}$ \\
\hline
\end{tabular}

Note: The criterion of the dynamic assessment of the oral test was written under the guidance of Common European Framework of Reference for languages: Learning, Teaching, Assessment [22].

The criterion was extended to the subjects before the oral test, whose topics were related to the content of the textbook. The assessment included two parts: self-statement; questions and answers. In the first part, when the speaker attained the certain level of Table 1, he/she would be marked with the scores given in Table 1. In the second part, the teacher and the peers would raise some questions. If the speaker could not understand the questions or answered them in an inaccurate way, or there were vocabulary or grammar mistakes, 0.1 score would be deducted.

The peer assessment and the teacher assessment of the oral teste were conducted in groups and in these ways. First, the form of Grade C. One of the group members made self-statement; then the teacher raised two or three questions; subsequently the rest of the group members marked the speaker's performance; the teacher also marked the speaker's performance. Second, the form of Grade B. The group members were divided into two parts: the conversation group and the audience. One of the members in the conversation group made self-statement first; then the members of the conversation group raised questions one by one; subsequently the teacher raised questions. Following that, the audience and the teacher marked the speaker's performance respectively. In order to ensure the validity of the peer assessment, the teacher chose some samples from the videos of the subjects in Grade 2015 (the videos of the oral tests while the previous study was carried out in Grade 2015) and showed them to the subjects in Grade 2017 before the oral test was held. The samples served as a reference to mark the peers. The whole processes of the oral tests of Grade C and Grade B were videoed.

The machine assessment referred to the subject's oral performances assessed on the mobile terminal. First, the form of Grade C. The teacher drafted the script and posted it on the learning platform of FiFEDU.com, from which the machine made a recording; the subject listened to the recording with the script on the mobile terminal and read the script aloud. The machine recorded the speaker's voice and marked his/her performance from these aspects: semantic meaning, pronunciation and fluency. Second, the form of Grade B. The teacher drafted the script and posted it on the learning platform of FiFEDU.com, from which the machine made a recording; the subject listened to the recording without the script on the mobile terminal and repeated the recording. The machine recorded the speaker's voice and marked his/her performance from these aspects: semantic meaning, pronunciation and fluency.

\section{Data Collection and Analysis}

\subsection{The Scores of the Placement Test}

Table 2 is the subjects' scores of the placement test (At the outset of the new term, all the new students in BUCT are required to take the placement test and are grouped into the advance, the intermediate and the adjustment classes according to their scores of the placement test), which were below the mean of the whole grade and is shown in Table 3. The exam paper was the Beijing unified college entry exam paper.

Table 2. The scores of the placement test (full marks: 100).

\begin{tabular}{lllllll}
\hline \multicolumn{1}{c}{ The Mean } & Total Scores & Listening & Reading & Vocabulary & Close \\
\cline { 1 - 3 } Functional Material 1701-02 & 41.4 & 9.57 & 18.59 & 7.51 & 5.68 \\
Mathematics 1707-Applied Chemistry 1707 & 41.9 & 7.92 & 20.04 & 7.96 & 5.58 \\
Machinery 1707-08-14 & 38.9 & 7.88 & 17.89 & 7.43 & 5.7 \\
\hline
\end{tabular}

Table 3. The comparison of the placement test. (full marks of listening: 20)

\begin{tabular}{lll}
\hline & The Mean & The Mean of Listening \\
\hline Grade 2017 & 41.28 & 8.53 \\
Subjects & 40.73 & 8.46 \\
\hline
\end{tabular}

\subsection{The Scores of Listening and Correlation Coefficient}

Table 4 are the scores of the online exams of New Horizon College English (Book 1 and Book 2) and the objective scores in the final exams of Grade $\mathrm{C}$ and Grade B. 
To verify the learning effect of New Horizon College English, the correlation coefficient [23] was made between the subjects' scores of the online exams and those of objective listening in the final exams, as is indicated in Table 5. Table 6 are the scores of dictation in the final exams.

Table 4. The scores of the online exams and the objective listening in the final exams.

\begin{tabular}{|c|c|c|c|c|}
\hline The Mean & Online Exam 1 & Online Exam 2 & Final Exam 1 & Final Exam 2 \\
\hline Class & Book 1 & Book 2 & Grade C & Grade B \\
\hline Functional Material 1701-02 & 37.6 & 32.15 & 13.16 & 14.04 \\
\hline Mathematics 1707-Applied Chemistry 1707 & 35.95 & 34.1 & 12.45 & 13.4 \\
\hline Machinery $1707-08-14$ & 34.65 & 30.25 & 11.56 & 12.98 \\
\hline
\end{tabular}

Note: The full marks of the online exam is 50 . The full marks of the objective listening in the final exam is 20 .

Table 5. The statistics of correlation coefficient.

\begin{tabular}{llc}
\hline Class & Correlation Coefficient & \multirow{2}{*}{ Online Exam 1 \& Final Exam 1 } \\
\hline Functional Material 1701-02 & 0.59 & 0.50 \\
Mathematics 1707-Applied Chemistry 1707 & 0.55 & 0.51 \\
Machinery 1707-08-14 & 0.53 & 0.38 \\
\hline
\end{tabular}

Table 6. The scores of dictation (full marks: 10).

\begin{tabular}{lll}
\hline Class & The Mean & Grade C \\
\hline Functional Material 1701-02 & Grade B \\
Mathematics 1707-Applied Chemistry 1707 & 4.46 & 5.37 \\
Machinery 1707-08-14 & 3.69 & 4.86 \\
\hline
\end{tabular}

\subsection{The Scores of Oral Tests}

The scores of the oral tests of Grade C and Grade B are shown in Table 7.

Table 7. The scores of oral tests (full marks: 5)

\begin{tabular}{|c|c|c|c|c|c|c|}
\hline \multirow[b]{2}{*}{ Class } & \multicolumn{3}{|l|}{ Grade C } & \multicolumn{3}{|l|}{ Grade B } \\
\hline & $\begin{array}{l}\text { Machine } \\
\text { Assessment }\end{array}$ & $\begin{array}{l}\text { Peer } \\
\text { Assessment }\end{array}$ & $\begin{array}{l}\text { Teacher } \\
\text { Assessment }\end{array}$ & $\begin{array}{l}\text { Machine } \\
\text { Assessment }\end{array}$ & $\begin{array}{l}\text { Peer } \\
\text { Assessment }\end{array}$ & $\begin{array}{l}\text { Teacher } \\
\text { Assessment }\end{array}$ \\
\hline Functional Material 1701-02 & 4.55 & 4.23 & 4.12 & 4.12 & 4.4 & 4.21 \\
\hline Mathematics 1707-Applied Chemistry 1707 & 4.52 & 4.08 & 4.01 & 4.09 & 4.35 & 4.26 \\
\hline Machinery $1707-08-14$ & 4.41 & 4.01 & 3.85 & 4.01 & 4.32 & 4.06 \\
\hline
\end{tabular}

Note: The oral tests of peer assessment and teacher assessment were held in the classroom, while those of machine assessment were made on the subjects' mobile terminals.

\subsection{Data Analysis}

As is indicated in Table 4, the accuracy ratio raised from $42.3 \%$ (the placement test) to $61.95 \%$ (Grade C) and to $67.37 \%$ (Grade B) respectively. The data in Table 5 reveal positive correlation between the scores of the web-based autonomous learning and the scores of the final exams, which shows that the majority of the subjects learned New Horizon College English earnestly, which also consolidated the previous research results of Grade 2015 in BUCT. The scores of Grade B of New Horizon College English (Online Exam 2 Book 2) were lower than those of Grade C (Online Exam 1 Book 1), because the content of Grade B was more difficult than that of Grade C. Similar data presented themselves in the case of Grade 2015 [11].

As is indicated in Table 6 , the accuracy ratio of dictation raised from $37.5 \%$ (Grade C) to $47.67 \%$ (Grade B). However, it failed to reach the accuracy ratio of above $60 \%$, which proves to be a difficult part for the subjects.

As is indicated in Table 7 , in the oral tests made on the mobile terminals, the scores of Grade B were lower than those of Grade $\mathrm{C}$ because of the different forms of the oral tests. The form of Grade B was repetition without the script and the subjects had to repeat the recording from their memory, which was more difficult than just reading the script aloud in Grade C. In the peer assessment of the oral test, the scores were higher than those of the teacher assessment. The data of both the peer and teacher assessment show that the subjects' oral English has improved.

\subsection{Unsolved Problems and Measures to Be Taken}

There exist some limitations in this research. (1) The validity and weakness in the assessment of the oral tests. The peer assessment can't be completely objective and some emotional factors might play some part. The machine assessment, which is limited to reading aloud or repetition, can't make assessment on the conversation among the subjects. (2) Heavy workload. In the teacher assessment, the teacher had to test 156 subjects, which took longer time to complete 
the oral tests. On the other hand, watching the videos by the subjects, making recorded comments, collecting the records on the mobile terminals and collecting the data of the web-based autonomous learning were time consuming. (3) The number of class periods. The discussion on the supplementary materials sometimes may take up the class periods of New Standard College English Real Communication An Integrated Course [24]. On account of the above reasons, the following measures need to be taken: (1) In the peer assessment, the assessment of their own oral work (the videos) should be added to lessen the subjectivity and emotional factors. (2) The extracurricular work such as the questions and answers on the mobile terminals, monitoring the progress of learning and sorting out the online learning records should be taken into the class periods. (3) The distinction between the listening and integrated class should be mitigated so that the teacher can deal with the teaching content flexibly.

\section{Conclusion}

The quality of the input of the mobile terminal learning, web-based autonomous learning was guaranteed by subjects' finishing the learning task as scheduled, submitting the self-assessment reports as well as raising questions online and by the teacher's tracking the subjects' learning processes, answering the questions online, offline as well as raising questions in class. The efficiency of "flipped classroom + face-to-face instruction" has been enhanced by the subjects' learning before class and by the teacher's carefully designing the teaching content. The supplementary materials built up the confidence of the subjects with poor listening ability. The subjects' output activities such as group discussion, making videos improved their collaborative skills. The peer correction of the scripts set the subjects thinking of their own learning behavior and thereby making proper adjustments of their learning strategies. By watching the subjects' videos and making recorded comments on each individual subject, the teacher could teach students according to their aptitude and satisfy their diverse needs to improve their oral English. The design of the dynamic assessment of the oral test enabled the subjects to get involved in the peer assessment in the oral tests, which created a more realistic environment in which real conversations were carried out. The scores of the oral tests on the machine, by the peer and by the teacher are rather close, which can reflect the subjects' oral ability more objectively. The correlation coefficient shows that the subjects' autonomy in learning has improved. The data also show that this teaching model does improve the subjects' listening and speaking ability, which also holds true that students have a high satisfaction at blended learning [9].

In this study, the teacher's leading role was manifested in all aspects of teaching: carefully designing the teaching content of the flipped class, raising the efficiency of face-to-face instruction of the video-aural-oral class, closely tracking the subjects' learning progress online and providing them with timely, personalized online and offline guidance. The students' principal part was manifested in the interaction with the resources, motivated autonomous learning, learning before the class, cooperative teamwork, peer study and self-reflection. All of these are the key elements in this teaching model. The conclusion has important reference significance on the research of blended learning.

\section{Acknowledgements}

We would like to thank the Dean's Office of Beijing University of Chemical Technology that funded our research: "The New Engineering Instruction Reform Project" (Project Number: xgk2017040745).

\section{References}

[1] Greenall S, Qiufang Wen. New Standard College English Real Communication Listening and Speaking (Second edition) [Z]. Beijing: Foreign Language Teaching and Research Press, 2017.

[2] Bonk C J, Graham C R, Cross J, et al. THE HANDBOOK OF BLENDED LEARNING: Global Perspectives, Local Designs [J]. Turkish Online Journal of Distance Education, 2009 (4): 181-181.

[3] Allen I E, Seaman J. Sizing the Opportunity: The Quality and Extent of Online Education in the United States, 2002 and 2003 [J]. The Sloan Consortium, 2003 (23): 659-673.

[4] Yen J C, Lee C Y. Exploring Problem Solving Patterns and Their Impact on Learning Achievement in A Blended Learning Environment [J]. Computers \& Education, 2011 (1): 138-145.

[5] Ke-kang He. On the Latest Development of the Theory of Educational Technology in the Angle of Blending Learning [J]. e-Education Research, 2004 (3): 1-6.

[6] Wasoh F. Exploring the Roles of Blended Learning as an Approach to Improve Teaching and Learning English. [EB/OL].[2016-11-17]. http:// web. a. ebscohost. com/ehost/pdfviewer/pdfviewer?sid=27144a22-f991-47c4a $39 \mathrm{e}-94160 \mathrm{e} 6 \mathrm{ce} 0 \mathrm{a} 9 \%$ 40sessionmgr4007\&vid $=0$ \&hid $=4214$.

[7] Jonathan B, Aaron S. Flipped Learning For Math Instruction [M]. Beijing: China Youth Press, 2018.

[8] Zhen LIU, Dai-wei ZHANG. Research on the Blending Learning based on the MOOC_— Taking the "Basic Principle of Marxism" Course for Example [J]. Modern Educational Technology, 2017, (11): 99-106.

[9] Xiaoying Feng, Ruixue Wang \& Yijun Wu. A Literature Review on Blended Learning: Based on Analytical Framework of Blended Learning [J]. Journal of Distance Education, 2018, (3) 13-24.

[10] Jiao-1an YAN, Wei-ran ZHANG, Yuan YU. School-based Flipped Classroom Teaching Reform on Video-aural-oral Course of College English — - A Case Study of BIPT [J]. Modern Educational Technology, 2016, (2): 94-100.

[11] Xiao-mei LIU. Study on the Innovative Blended Visual-aural-oral Teaching Model College English-Taking Beijing University of Chemical Technology as an Example [J]. Modern Educational Technology 2016, (11): 100-106. 
[12] Shu-tang Zheng, Zhong Xu. New Horizon College English: Speaking Listening Viewing (Second edition) [Z]. Beijing: Foreign Language Teaching and Research Press, 2013.

[13] Gass S M. \& Mackey A. Input, interaction, and output in second language acquisition [A]. B. Vanpatten \& J. Williams (ed.), Theories in Second Language Acquisition [C]. Mahwah, NJ: Lawrence Erlbaum Associates, 2007, 175-99.

[14] Qiufang Wen. Application of the output-driven hypothesis in college English teaching; Reflections and suggestions. [J]. Foreign Language World, 2013, (6): 14-22.

[15] Tyler, R. W. Basic Principles of Curriculum and Instruction [M]. Chicago: The University of Chicago Press, 1949.

[16] The National Foreign Languages Teaching Advisory Board, Ministry of Education. Guidelines on College English Teaching [Z]. 2017. https://wenku.baidu.com/view/a514b9865ebfc77da26925c52c c58bd63086936d.html.

[17] Kinsella K. Understanding and empowering diverse learners in ESL classrooms [A]. Reid J M. Learning styles in the ESL/EFL classroom [C]. Beijing: Foreign Language Teaching and Research Press, 2002: 193.

[18] Gass S, Svetics I. \& Lemelin S. Differential effects of attention. Language Learning. [J]. 2003, 53 (3): 495-543.
[19] Goodyear V, Dudley D. "I'm a Facilitator of Learning!" Understanding What Teachers and Students Do Within Student-Centered Physical Education Models [J]. Quest, 2015 (3): $274-289$.

[20] Qiufang Wen. Major Issues in Second Language acquisition [M]. Beijing: Foreign Language Teaching and Research Press, 2010: 285-64.

[21] Miyazoe T, Anderson T. Viewing and Participating: Blog Visualization and Its Learning Outcomes in Blended Learning $[\mathrm{C}] / /$ Professional Communication Conference. IEEE, 2011: $1-9$.

[22] The Council of Europe, Common European Framework of Reference for languages: Learning, Teaching, Assessment [Z]. Beijing: Foreign Language Teaching and Research Press, 2014.

[23] Bao-cheng Han. Statistics in Foreign Language Teaching and Research [Z]. Beijing: Foreign Language Teaching and Research Press, 2004: 126-131.

[24] Greenall S, Qiufang Wen. New Standard College English Real Communication An Integrated Course (Second edition) [Z]. Beijing: Foreign Language Teaching and Research Press, 2016. 